\title{
19S IgM Rheumatoid Factor-7S IgG Rheumatoid Factor Immune Complexes Isolated in Sera of Patients with Juvenile Rheumatoid Arthritis
}

\author{
TERRY L. MOORE, THOMAS G. OSBORN, AND ROBERT W. DORNER \\ Departments of Internal Medicine and Pediatrics-Adolescent Medicine, Division of Rheumatology, St. Louis \\ University School of Medicine and Cardinal Glennon Children's Hospital, St. Louis, Missouri 63104
}

\begin{abstract}
S IgM rheumatoid factors (RF) and hidden 19S IgM RF have been associated with increased disease activity in juvenile rheumatoid arthritis (JRA). Recently, immune complexes (IC) were isolated from JRA sera by several methods which demonstrated the presence of 19S IgM RF. The present study evaluates 25 JRA patients' sera by separation on a Sepharose $4 \mathrm{~B}$ column to which were bound $F\left(a b^{\prime}\right)_{2}$ fragments of goat IgG antihuman IgM antibody to separate IgM-containing IC. The columns were sequentially eluted with $1 \mathrm{M}$ ammonia and 0.1 M glycine-HCl buffer, pH 3.0. The isolated fractions were assayed for 19S IgM RF and 7S IgM RF by ELISA, IgG levels by immunodiffusion, and by preparative isoelectric focusing. The ammonia eluate from the $\alpha$ HIgM column revealed IgG, 19S IgM RF in six patients, and IgM RF in four patients. All were polyarticular-onset JRA patients. In the glycine-HCl eluate of sera, 19S IgM RF and IgG were also detected in 15 patients, all six seropositive, polyarticular-onset, six seronegative, polyarticular-onset, and three pauciarticular-onset patients. Significant 7S IgG RF titers were demonstrated in the glycine-HCl eluates of six patients, five seropositive, polyarticular-onset patients, and one seronegative, polyarticular-onset patient. Analysis by preparative isoelectric focusing of the IgM RF and IgG RF positive ammonia and glycine-HCl eluates showed IgM $\mathrm{RF}$ throughout the $\mathrm{pH}$ range (4-10), but the highest amount of IgM RF was in the $\mathrm{pH}$ range 4.0-5.5. Significant IgG RF titers were detected only in this restricted spectrotypic area of $\mathrm{pH} \mathrm{4.0-5.5}$. These studies demonstrate ICcontaining 19S IgM RF-IgG and 19S IgM RF-7S IgG RF can be detected in JRA patients' sera. The 19S IgM RF and IgG RF when present are predominantly found in the pH band $4.0-5.5$ by preparative isoelectric focusing. The ability to isolate IC containing $19 \mathrm{~S}$ IgM RF as a marker in this $\mathrm{pH}$ band may relate to active disease. Further determination of the constituents of the IC may help in defining the antigen in JRA and understanding the pathophysiologic mechanisms of the disease. (Pediatr Res 20: 977-981, 1986)
\end{abstract}

Received December 13, 1985; accepted May 21, 1986.

Address for correspondence and reprint requests to Terry L. Moore, M.D. Professor of Internal Medicine and Pediatrics-Adolescent Medicine, Director, Division of Rheumatology, St. Louis University School of Medicine, Room R215 Doisy Hall, 1402 South Grand Boulevard, St. Louis, MO 63104.

Supported in part by grants from the National Institutes of Health, a Research Career Development Award (AM-01036, Dr. Moore), Employees Charity Community Services of the McDonnell-Douglas Corporation of St. Louis, Easter Seal Research Foundation, and money given In Memory of Kristen and Deron Geuder, John Dunlap, and Roy Levin for research in children's rheumatic diseases.
Abbreviations

\author{
$\alpha$ HIgM, antihuman IgM \\ BBS, borate buffered saline \\ ELISA, enzyme-linked immunosorbent assays \\ IC, immune complexes \\ IEF, isoelectric focusing \\ JRA, juvenile rheumatoid arthritis \\ $\mathrm{NH}_{3}$, ammonia \\ PBS, phosphate-buffered saline \\ PEG, polyethylene glycol \\ $\mathrm{RF}$, rheumatoid factors
}

IC have been demonstrated in the sera of patients with JRA utilizing various assays (1). The frequency with which these IC can be detected depends on the assay, type of disease onset, and activity of disease (2-4). IC have been detected in as high as $79 \%$ of JRA patients by at least one assay method, the highest percentage being found by either the Clq binding assay or Clq solidphase assay (2-4). The presence of IC has been detected in all JRA onset types, but the highest percentage are found in the polyarticular-onset, 19S IgM RF positive and systemic onset (24). The presence of elevated IC as detected by the Clq binding assay or the $\mathrm{Clq}$ solid-phase assay, also, correlated with the presence of 19S IgM RF $(2,3)$ and hidden 19S IgM RF (3) [i.e. 19S IgM RF which can be detected in the IgM-containing fraction by the hemolytic assay after separation of serum by acidgel filtration $(5,6)]$. IC presence has also correlated with active disease, demonstrating a connection with a more advanced stage of disease and possible prognostic parameter $(3,4)$.

Because of these original observations $(2,3)$, we attempted to develop several IC separation procedures to further evaluate the IC to determine if possible antigenic constituents could be described (7-9). In preliminary studies, we have shown that IC from the sera of patients with polyarticular onset and pauciarticular onset JRA could be separated and characterized by the use of the $\alpha \mathrm{HIgM}$ affinity column and PEG precipitation-acid treatment. In ten JRA patients' sera, IC that contained both IgM $\mathrm{RF}$ and IgG were found by these methods (7). We have also demonstrated that IC can be separated from serum and synovial fluid of patients with JRA using PEG to precipitate IC and subsequently Staphylococcal protein A to separate the IC (8). Ten of 16 JRA patients' sera and three of five JRA patients' synovial fluids showed significant $19 \mathrm{~S}$ IgM RF titers and IgG levels in their acid eluates separated by the PEG-Staphylococcal protein A method (8). Sucrose density gradient analysis of these sera demonstrated elevated levels of IC detected by the Clq solidphase assay in the fractions $\geq 19 \mathrm{~S}$, comparable to the previously isolated 19S IgM RF-IgG complexes (8). In a recent study, we 
also were able to isolate complement-fixing IC from the sera of patients with JRA using immunosorbent columns with bound antihuman Clq and antihuman C3 (9). Using sequential elution of the columns, 19S IgM RF were detected in one or more separated IC fractions in 13 of 14 patients and IgG RF in three patients utilizing the antihuman Clq. Using the antihuman C3 column, only five patients demonstrated IgM RF and only one IgG RF in the eluted fractions. Again, by sucrose density gradient analysis, all IC were demonstrated in peaks $\geq 19 \mathrm{~S}$. These preliminary studies demonstrating the ability to detect IC-like material containing 19S IgM RF, 7S IgG RF, and IgG in JRA supports participation of classic 19S IgM RF and hidden 19S IgM RF in IC formation in JRA patients (7-9). Previous studies had demonstrated the association of active disease in JRA patients with polyarticular and pauciarticular onset who had 19S IgM RF or hidden 19S IgM RF circulating in their sera $(5,6)$. The new findings of the 19S IgM RF association with IC formation in JRA initiated the present study. We were interested in isolating IC from a large number of JRA patients by the $\alpha \mathrm{HIgM}$ affinity column method to determine the constituents of the IC and to further characterize them by IEF. The possible short-term goals were to establish a method that would determine pathogenic IC in JRA which would relate to disease activity and prognosis. The long-term goals were to develop a method which would lead to the ability to determine the constituents of the IC and possible underlying antigen in JRA.

\section{METHODS}

Patient population. Blood was drawn from 25 children who were outpatients at the St. Louis University Children's Arthritis Clinic at Cardinal Glennon Children's Hospital, St. Louis University Doctors' Office Building, or private patients of Division rheumatologists. All patients were informed of the nature of the studies which have been previously approved by the St. Louis University Institutional Review Board and their parents were asked for written consent. Only patients meeting the criteria for diagnosis of JRA established by the Committee on JRA of The American Rheumatism Association were included (10).

Specimen collection. Blood was drawn into clot tubes and allowed to clot for $3 \mathrm{~h}$ at $37^{\circ} \mathrm{C}$. It was then centrifuged at 2000 $\mathrm{rpm}$ for $5 \mathrm{~min}$ at room temperature. The serum was aspirated and stored at $-70^{\circ} \mathrm{C}$ until evaluated.

Isolation of immune complexes by antihuman IgM affinity column. The method was performed with modifications as described by Jones et al. (11). The IgG fraction of rabbit $\alpha \mathrm{HIgM}$ serum (Behring Diagnostics, Somerville, NJ) was separated by DEAE-cellulose chromatography, concentrated, and digested with pepsin. The resulting $\mathrm{F}\left(\mathrm{ab}^{\prime}\right)_{2}$ fragments were isolated by gel filtration on Sephadex G-200 in 0.15 M PBS, pH 7.4 (PBS) at room temperature. The $\mathrm{F}\left(\mathrm{ab}^{\prime}\right)_{2}$ fragments were coupled to cyanogen bromide activated Sepharose 4B (Sigma Chemical Co., St. Louis, MO) according to Pharmacia directions. One $\mathrm{ml}$ of $\mathrm{F}\left(\mathrm{ab}^{\prime}\right)_{2}$ coupled gel was packed into a 3-ml syringe. One $\mathrm{ml}$ of patient's serum was applied to the column and incubated for $1 \mathrm{~h}$ at room temperature. The column was eluted with $\mathrm{BBS}, \mathrm{pH}$ 8.0. The void volume was discarded and three $1 \mathrm{ml}$ fractions were collected while eluting with BBS. The column was then washed with BBS and $1 \mathrm{M} \mathrm{NH}_{3}$ was applied. Three 1-ml fractions were collected and immediately neutralized with $1 \mathrm{M}$ propionic acid. Finally, $0.1 \mathrm{M}$ glycine- $\mathrm{HCl}, \mathrm{pH} 3.0$ was applied and three $1-\mathrm{ml}$ fractions were collected and neutralized with $0.1 \mathrm{~N} \mathrm{NaOH}$. Individual fractions were stored at $-70^{\circ} \mathrm{C}$. A column was prepared as above with $\mathrm{F}\left(\mathrm{ab}^{\prime}\right)_{2}$ fragments of goat IgG with no immunologic specificity bound to Sepharose 4B for control.

ELISA for 19SIgM RF. The assay was performed with modification of the methods described by Faith et al. (12). Two hundred $\mu \mathrm{l}$ of $5 \mu \mathrm{g} / \mathrm{ml}$ human $\mathrm{IgG}$ in $0.1 \mathrm{M} \mathrm{NaHCO}_{3}$ were added to the wells of microtiter plates (Dynatech Labs, Inc., Alexandria, VA) and incubated overnight at $4^{\circ} \mathrm{C}$. The microtiter wells were washed three times with PBS-Tween and samples, serially diluted from 1:10 to 1:1280, added. After overnight incubation, the wells were washed three times with PBS-Tween. Two hundred $\mu 1$ of an alkaline phosphatase-conjugated goat $\alpha$ HIgM solution (Sigma Chemical Co.), diluted 1:1000 in PBS-Tween were added and left at room temperature for $2 \mathrm{~h}$. The wells were subsequently washed three times with PBS-Tween and once with double distilled water. Finally, $200 \mu$ l of substrate solution (1 mg of Sigma 104 phosphatase substrate in PBS-Tween along with $1 \mathrm{M}$ diethanolamine buffer, $\mathrm{pH} 9.7$ with $0.5 \mathrm{mM}$ magnesium) chloride was added to each well. The reaction was stopped after 10 min at room temperature by addition of $100 \mu \mathrm{l}$ of $3 \mathrm{M} \mathrm{NaOH}$. Absorbance was read on a micro-ELISA mini reader [Dynatech (model MR-590)] to determine the titer of the IgM RF [titers > $1: 16$ are considered significant compared to healthy controls (9)].

ELISA for $7 S I g G R F$. The assay was performed with modifications of the method of Faith et al. (12). Two hundred $\mu \mathrm{l}$ of $10 \mu \mathrm{g} / \mathrm{ml}$ rabbit $\mathrm{IgG}$ in $0.1 \mathrm{M} \mathrm{NaHCO}_{2}$ were added to microtiter plate wells and incubated overnight at $4^{\circ} \mathrm{C}$. The microtiter plates were washed three times with PBS-Tween and allowed to dry. Twenty $\mu$ l of patient's serum sample were diluted 1:50 in pepsinacetate buffer (10 $\mu \mathrm{g}$ pepsin/ml $0.1 \mathrm{M}$ acetate buffer, $\mathrm{pH} 4.4$ ), incubated overnight at $37^{\circ} \mathrm{C}$, and neutralized with equal volumes of PBS-Tween containing $80 \mathrm{mg}$ disodium hydrogen phosphate/ $\mathrm{ml}$. Two hundred $\mu \mathrm{l}$ of pepsin digested sera were added to each well and incubated overnight at room temperature. Plates were washed three times with PBS-Tween. Two hundred $\mu$ l of glucose oxidase conjugated $\mathrm{F}\left(\mathrm{ab}^{\prime}\right)_{2}$ fragments of goat $\alpha \mathrm{HIgG}$ diluted 1:1000 in PBS-Tween were added to each well and incubated for $2 \mathrm{~h}$ at $37^{\circ} \mathrm{C}$. Plates were again washed three times with PBSTween followed by the addition of $200 \mu \mathrm{l}$ of substrate solution to each well and incubation for $1 \mathrm{~h}$ at room temperature. Finally, the reaction was stopped by the addition of $100 \mu \mathrm{l}$ of $3 \mathrm{M} \mathrm{NaOH}$ and read as above for the IgM RF-ELISA assay [titers $>1: 16$ are considered significant compared to healthy controls (8)].

Hemolytic assay for the presence of $19 S \operatorname{IgM} R F$. The assay was performed on the IgM-containing fractions from a Sephadex G-200 column as previously described in detail $(5,6)$.

IgG level measurement in immune complexes. Low level radial immunodiffusion plates (Behring-Calbiochem, La Jolla, CA) were used to measure IgG levels on $\alpha \mathrm{HIgM}$ affinity column fractions.

$I E F$. The method of Manrique and Lansky (13) was used with minor modifications. A 2-ml sample was desalted by dialysis or by passing the sample over a Sephadex G-25 column in the proper ampholyte. A mixed agarose-Sephadex IEF [2.5 g Sephadex IEF (Ultradex), $0.5 \mathrm{gm}$ Agarose IEF, $8.0 \mathrm{~g}$ Sorbitol, and $91.3 \mathrm{ml}$ double distilled water] gel was prepared. The gel was attached to a power supply and run for $8-10 \mathrm{~h}$ at $4^{\circ} \mathrm{C}$ at a constant power of $15 \mathrm{~W}$. The run was stopped when properly focused and a print was made. The paper was fixed with trichloroacetic acid (10-20\%) for $10-15 \mathrm{~min}$ and stained with $0.2 \%$ Coomassie blue in a 50:50:10 methanol/ $\mathrm{H}_{2} \mathrm{O}$ /acetic acid mixture for $15 \mathrm{~min}$. The gel was fractionated by pressing a 30 -slot grid firmly into the gel. Each fraction was composed of two gel strips in 2-4 $\mathrm{ml} \mathrm{H}_{2} \mathrm{O}$ for a total of 15 fractions. The fractions were crushed thoroughly. The $\mathrm{pH}$ of each fraction was determined and the mixture frozen at $-20^{\circ} \mathrm{C}$. The fractions were thawed and centrifuged at $3000 \mathrm{rpm}$ for $10 \mathrm{~min}$ to precipitate insoluble gel. The supernatants containing the protein fractions were analyzed as described above.

\section{RESULTS}

Sera was collected from 25 children with JRA, six polyarticular onset, seropositive for 19S IgM RF, 12 polyarticular onset, seronegative, and seven pauciarticular onset (Table 1). The sera were subjected to affinity chromatography on an $\alpha \mathrm{HIgM}$ affinity column. The resultant fractions were tested for 19S IgM RF and 
Table 1. JRA patients' onset type, 19S IgM RF and 7S IgG RF in sera, and hidden 19S IgM RF titer in IgM-containing fraction from Sephadex $G-200$ separation

\begin{tabular}{|c|c|c|c|c|}
\hline Patient & Onset type & $\begin{array}{l}\text { 19S IgM RF } \\
\text { by ELISA } \\
\text { on serum }\end{array}$ & $\begin{array}{l}\text { 7S IgG RF by ELISA } \\
\text { (1:20 dilution) on } \\
\text { serum }\end{array}$ & $\begin{array}{l}\text { 19S IgM RF by } \\
\text { hemolytic assay in } \\
\text { IgM-containing } \\
\text { fraction }\end{array}$ \\
\hline $\mathrm{Pg}$ & (Poly)* & $1: 10,240$ & + & $1: 128$ \\
\hline $\mathrm{Dg}$ & (Poly) & $1: 5120$ & + & $1: 512$ \\
\hline $\mathrm{Ab}$ & (Poly) & $1: 5120$ & + & $1: 1024$ \\
\hline Ns & (Poly) & $1: 5120$ & + & $1: 1024$ \\
\hline $\mathrm{Cr}$ & (Poly) & $1: 5120$ & + & $1: 64$ \\
\hline $\mathrm{Km}$ & (Poly) & $1: 640$ & + & $1: 64$ \\
\hline $\mathrm{Sc}$ & (Poly) & NEG & + & $1: 128$ \\
\hline $\mathrm{Jh}$ & (Poly) & NEG & + & $1: 64$ \\
\hline $\mathrm{Nz}$ & (Poly) & NEG & + & $1: 32$ \\
\hline Tw & (Poly) & NEG & NEG & NEG \\
\hline $\mathrm{Tb}$ & (Poly) & NEG & + & NEG \\
\hline $\mathrm{Vc}$ & (Poly) & NEG & NEG & NEG \\
\hline $\mathrm{Sm}$ & (Poly) & NEG & NEG & $1: 32$ \\
\hline $\mathrm{Td}$ & (Poly) & NEG & + & $1: 128$ \\
\hline $\mathrm{Db}$ & (Poly) & NEG & NEG & $1: 16$ \\
\hline $\mathrm{Bl}$ & (Poly) & NEG & NEG & $1: 256$ \\
\hline Rt & (Poly) & NEG & NEG & NEG \\
\hline Ww & (Poly) & NEG & NEG & $1: 32$ \\
\hline $\mathrm{Jc}$ & (Pauci) $\dagger$ & NEG & NEG & $1: 32$ \\
\hline $\mathrm{Dd}$ & (Pauci) & NEG & NEG & $1: 16$ \\
\hline $\mathrm{Ae}$ & (Pauci) & NEG & NEG & $1: 16$ \\
\hline $\mathrm{Jp}$ & (Pauci) & NEG & NEG & $1: 16$ \\
\hline $\mathrm{Nr}$ & (Pauci) & NEG & NEG & NEG \\
\hline Ac & (Pauci) & NEG & NEG & $1: 64$ \\
\hline $\mathrm{Mh}$ & (Pauci) & NEG & NEG & $1: 32$ \\
\hline
\end{tabular}

* Polyarticular onset JRA.

$\uparrow$ Pauciarticular onset JRA.

7S IgG RF by ELISA, and IgG immunoglobulins by low level radial immunodiffusion (Table 2). Of the 25 patients, six were seropositive for IgM RF in their sera, 10 others had significant hidden 19S IgM RF titers in the IgM-containing fraction obtained by gel filtration of their sera at acid $\mathrm{pH}$, and nine had insignificant titers for IgM RF both in their sera and in their IgM-containing fractions from Sephadex G-200 column chromatography (Table 1). Eleven patients (six seropositive and five seronegative, polyarticular onset) demonstrated IgG RF by ELISA in their sera (Table 1). The columns were eluted with $\mathrm{NH}_{3}$ and glycine- $\mathrm{HCl}$. In the $\mathrm{NH}_{3}$ eluted fractions, eight patients (all six seropositive and two seronegative, polyarticular onset patients) demonstrated IgG and elevated 19S IgM RF titers by ELISA and five of the six seropositive, polyarticular-onset patients also demonstrated elevated IgG RF titers (Table 2). Significant 19S IgM RF titers were also detected in 15 patients in the glycine- $\mathrm{HCl}$ eluates, including all six seropositive, polyarticular onset and six seronegative, polyarticular onset and three pauciarticular onset patients of which eight demonstrated hidden 19S IgM RF in their sera (Table 2). Significant 7S IgG RF titers were demonstrated in seven patients' glycine- $\mathrm{HCl}$ eluate, all six seropositive, polyarticular onset patients and one seronegative, polyarticular onset patient (Table 2). Overall, 13 of 18 polyarticular onset and three of seven pauciarticular onset had 19S IgM RF detected in their isolated IC; whereas, only seven demonstrated IgG RF, all six IgM RF positive and one seronegative, polyarticular onset patients. Fifteen of the 16 patients demonstrating IgM RF and IgG RF or IgM RF alone in the $\mathrm{NH}_{3}$ or glycine- $\mathrm{HCl}$ eluates had significant levels of $\mathrm{IgG}$ detected by radial immunodiffusion. Only one patient (Jh) with IgM RF in the glycine eluate showed no evidence of complexed IgG (Table 2). Four patients sera $(\mathrm{Pg}, \mathrm{Ab}, \mathrm{Ns}, \mathrm{Km})$ with high levels of $\mathrm{IgG}$ by radial immunodiffusion in their glycine- $\mathrm{HCl}$ eluates from $\alpha$ HIgM column were applied to the control column which had
$\mathrm{F}\left(\mathrm{ab}^{\prime}\right)_{2}$ fragments of goat IgG bound. All four patients demonstrated no $\mathrm{IgG}$ in their $\mathrm{NH}_{3}$ on glycine- $\mathrm{HCl}$ eluates from the column. One patient (Td) demonstrated IgM RF by ELISA in her BBS washed fraction and no IgM RF in the $\mathrm{NH}_{3}$ or glycine$\mathrm{HCl}$ eluate (Table 2). This was also seen in the BBS fractions of four patients when tested for IgG RF (Jh, Nz, Tb, Td) (Table 2). Sera from five healthy children used as controls had no IgM RF or IgG RF by ELISA or IgG in the $\mathrm{NH}_{3}$ or glycine- $\mathrm{HCl}$ eluates.

The $\mathrm{NH}$ and glycine- $\mathrm{HCl}$ eluates, positive for IgM RF and IgG $\mathrm{RF}$, were subsequently analyzed by preparative IEF. On evaluation of the IEF fractions, 19S IgM RF were detected throughout the $\mathrm{pH}$ range, but predominantly acidic proteins with isoelectric points of 4.0-5.5. A typical IEF pattern is shown in Figure 1 and the 19S IgM RF and 7S IgG RF titers of the resulting fractions in Table 3. The IgG RF demonstrated a restricted spectrotype pattern being found mainly in the $\mathrm{pH}$ range of 4.0-5.5 (Table $3)$.

\section{DISCUSSION}

IC have been detected by several methods in the sera of patients with JRA (1-4). IC presence correlated with the presence of 19S $\operatorname{IgM} \operatorname{RF}(2,3)$, hidden $19 \mathrm{~S} \operatorname{IgM}$ RF $(3)$, and active disease $(3,4)$ in early studies. Further separation and characterization of IC in the sera of patients with JRA utilizing various procedures also demonstrated the presence of $19 \mathrm{~S}$ IgM RF, 7S IgG, and 7S IgG RF in these IC (7-9). The same IC were demonstrated to be complement-fixing by use of immunosorbent columns to which were bound antihuman Clq and antihuman C3 (9). These previous studies have supported the participation of classic 19S IgM $\mathrm{RF}$, 7S IgG RF, IgG, and hidden $19 \mathrm{~S}$ IgM RF in IC formation in JRA patients.

The present study demonstrates IC-like material can be detected in the sera of a large number of JRA patients after 
Table 2. 19S IgM RF and 7S IgG RF titers by ELISA in $\mathrm{NH}_{3}$ and glycine-HCl eluates from $\alpha$ HIgM affinity column

\begin{tabular}{|c|c|c|c|c|c|c|c|}
\hline \multirow[b]{2}{*}{ Patient } & \multicolumn{3}{|c|}{ IgM RF } & \multicolumn{3}{|c|}{ IgG RF } & \multirow{2}{*}{$\begin{array}{l}\text { IgG by RID on } \\
\text { glycine- } \mathrm{HCl} \\
\text { eluate }(\mu \mathrm{g} / \mathrm{ml})\end{array}$} \\
\hline & BBS & $\mathrm{NH}_{3}$ & Gly-HCl & BBS & $\mathrm{NH}_{3}$ & Gly-HCI & \\
\hline Pg* & $1: 384 \dagger$ & $1: 384$ & $1: 384$ & $1: 384$ & $1: 24$ & 1.48 & 110 \\
\hline $\mathrm{Dg}^{*}$ & $1: 384$ & 1:96 & $1: 384$ & $>1: 384$ & $1: 48$ & $1: 384$ & 180 \\
\hline $\mathrm{Ab}^{*}$ & $>1: 384$ & $>1: 384$ & $>1: 384$ & $>1: 384$ & $>1: 384$ & $1: 96$ & 420 \\
\hline $\mathrm{Ns}^{*}$ & $>1: 384$ & $1: 96$ & $>1: 384$ & $>1: 384$ & 1:192 & $1: 48$ & 90 \\
\hline $\mathrm{Cr}^{*}$ & $1: 192$ & 1:96 & 1:192 & 1:192 & NEG & $1: 96$ & 70 \\
\hline $\mathrm{Km}^{*}$ & $1: 48$ & $1: 96$ & $1: 384$ & NEG & $1: 24$ & $1: 96$ & 210 \\
\hline $\mathrm{Sc}$ & $1: 24$ & $1: 384$ & $1: 384$ & $1: 96$ & NEG & $1: 192$ & 10 \\
\hline $\mathrm{Jh}$ & $1: 24$ & NEG & $1: 24$ & 1:192 & NEG & $1: 12$ & NEG \\
\hline $\mathrm{Nz}$ & $1: 12$ & $1: 48$ & NEG & $1: 96$ & NEG & $1: 12$ & NEG \\
\hline Tw & NEG & NEG & $1: 24$ & NEG & NEG & NEG & 10 \\
\hline $\mathrm{Tb}$ & $1: 12$ & $1: 12$ & $1: 12$ & $1: 24$ & NEG & NEG & NEG \\
\hline $\mathrm{Vc}$ & NEG & NEG & $1: 12$ & NEG & NEG & NEG & NEG \\
\hline Sm & NEG & $\mathrm{NEG}$ & $1: 24$ & NEG & NEG & NEG & 10 \\
\hline $\mathrm{Td}$ & $1: 48$ & NEG & $1: 12$ & $1: 96$ & NEG & NEG & NEG \\
\hline $\mathrm{Db}$ & NEG & NEG & NEG & NEG & NEG & NEG & NEG \\
\hline $\mathrm{Bl}$ & NEG & NEG & 1:96 & NEG & NEG & NEG & 10 \\
\hline $\mathrm{Rt}$ & NEG & NEG & NEG & NEG & NEG & NEG & $\mathrm{NEG}$ \\
\hline Ww & $1: 12$ & NEG & $1: 24$ & NEG & NEG & $1: 12$ & 10 \\
\hline $\mathrm{Jc}$ & NEG & NEG & $1: 24$ & NEG & NEG & NEG & 10 \\
\hline Dd & NEG & NEG & NEG & NEG & NEG & NEG & NEG \\
\hline $\mathrm{Ae}$ & NEG & NEG & NEG & NEG & NEG & NEG & NEG \\
\hline $\mathrm{Jp}$ & NEG & NEG & $1: 24$ & NEG & NEG & NEG & 10 \\
\hline $\mathrm{Nr}$ & NEG & NEG & NEG & NEG & NEG & NEG & NEG \\
\hline Ac & NEG & NEG & NEG & NEG & NEG & NEG & NEG \\
\hline Mh & $1: 12$ & NEG & $1: 24$ & NEG & NEG & NEG & 10 \\
\hline
\end{tabular}

* RF positive in serum.

$\dagger$ Dilution 1:6 of material coming off the column after elution.

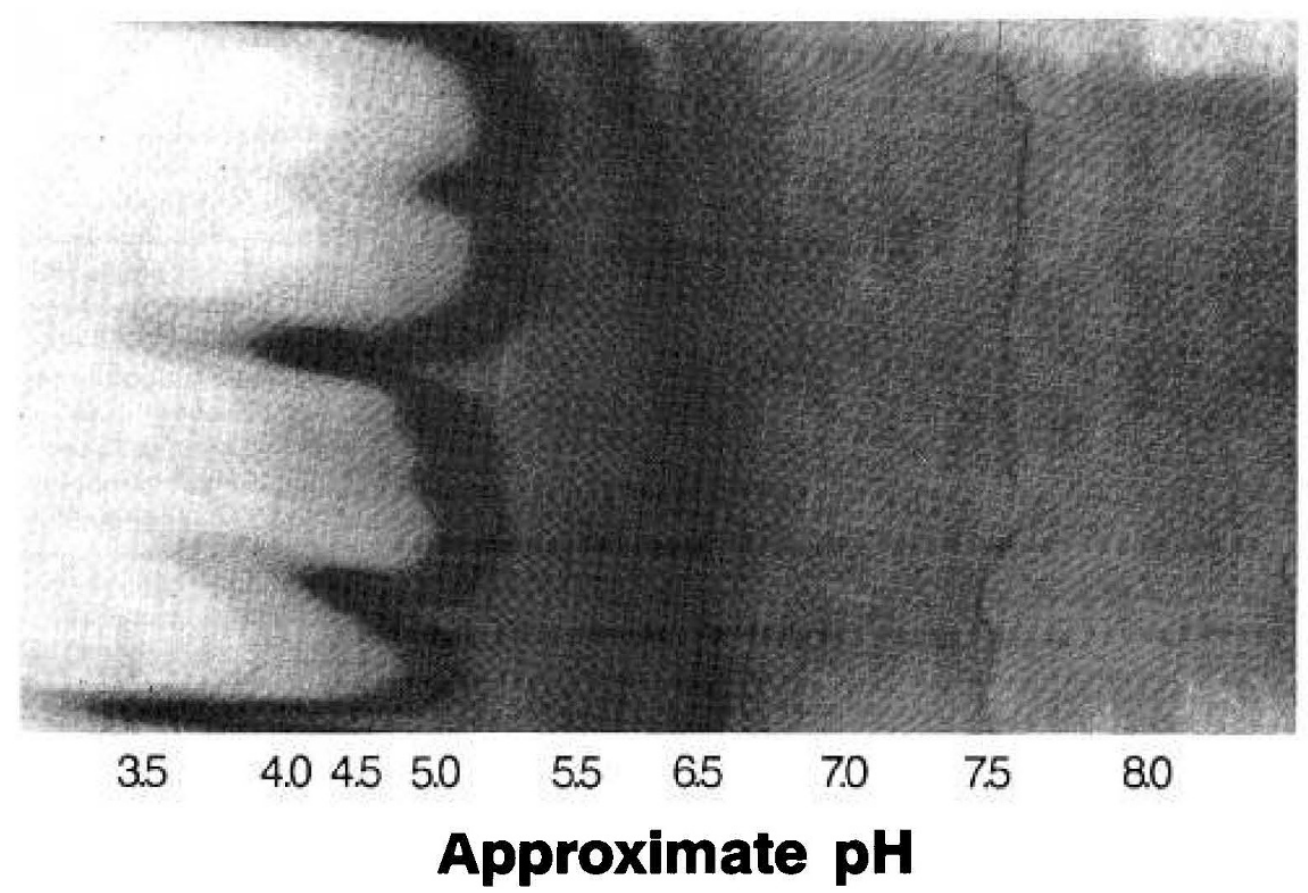

Fig. 1. Spectrotype pattern of glycine- $\mathrm{HCl}$ eluate from $\alpha \mathrm{HIgM}$ affinity column of patient $(\mathrm{Dg})$ demonstrating predominant levels of proteins in pH range 4.0-5.5.

separation and elution from an $\alpha \mathrm{HIgM}$ affinity column. By eluting with $\mathrm{NH}_{3}$ or glycine- $\mathrm{HCl}$, IC containing 19S IgM RFIgG and 19S IgM RF-7S IgG RF could be demonstrated in the eluted fractions. Sixteen of the 25 patients, 13 polyarticular onset and three pauciarticular onset, studied demonstrated 19S IgM RF in their isolated IC. Six were seropositive and nine of the other 10 had previously demonstrated hidden 19S IgM RF in their IgM-containing fraction produced by acid-gel separation of their sera. IgG RF were only demonstrated in seven patients, six seropositive and one seronegative, polyarticular onset patient, who had hidden 19S IgM RF in her serum. These results are similar to findings in adult RA patients in that all the seropositive 
Table 3. $19 S$ IgM RF and 7S IgG RF titers by ELISA of fractions from IEF of IC in glycine- $\mathrm{HCl}$ eluate from patient $\mathrm{Dg}$

\begin{tabular}{ccl}
\hline $\mathrm{pH}$ range & IgM RF & IgG RF \\
\hline$<4.0$ & $1: 384^{*}$ & NEG \\
$4.0-4.5$ & $1: 1536$ & $1: 96$ \\
$4.5-5.0$ & $1: 1536$ & $1: 192$ \\
$5.0-5.5$ & $1: 1536$ & $1: 96$ \\
$5.5-6.0$ & $1: 384$ & $1: 24$ \\
$6.0-6.9$ & $1: 192$ & NEG \\
$7.0-7.9$ & $1: 192$ & NEG \\
$>8.0$ & $1: 192$ & NEG \\
\hline
\end{tabular}

* Dilution 1:6 of material coming off the column after elution.

patients demonstrated both $19 \mathrm{~S} \mathrm{IgM} \mathrm{RF}$ and $7 \mathrm{~S}$ IgG RF in their IC (11). The presence of both RF usually is seen in adult patients with more severe disease and worse prognosis (11). This suggests a common etiology of these six polyarticular onset patients and adult patients with RA. All seven of the patients with IgG RF in their IC have severe, polyarticular disease being treated with gold salts. Nine of the other 10 who demonstrated significant $19 \mathrm{~S}$ IgM RF titers in their isolated IC also had hidden 19S IgM RF in their sera. These patients will have to be followed to see if the presence of these IC denotes a worse prognosis.

The reason why nine patients had significant 19S IgM RF titers in the BBS fraction is not clear. It is conceivable that IgM $\mathrm{RF}$ formation with $\mathrm{IgG}$ or IgG RF results in steric hindrance thus preventing firm attachment of the IgM RF to the $\alpha \mathrm{HIgM}$ affinity column. Alternatively, saturation of the affinity column has to be considered also, since all $\alpha \mathrm{HIgM}$ antibodies cannot be expected to have equally strong avidity for IgM.

Fifteen of the 16 patients had $\mathrm{IgG}$ detected in their eluates. The findings of the IgG and IgG RF in the eluates demonstrated the presence of IC. The IgG most likely had to be bound to the $19 \mathrm{~S}$ IgM RF or in combination with $19 \mathrm{~S}$ IgM RF and 7S IgG $\mathrm{RF}$, because the column was specific for binding of only human $\mathrm{IgM}$. However, the possibility of naturally occurring IgG anti$\mathrm{F}\left(\mathrm{ab}^{\prime}\right)_{2}$ or anti-Fab antibodies which have been detected in patients with RA (14-16) and JRA (17) could account for the $\mathrm{IgG}$ in the immune complex containing eluates. They could account for a small portion of the IgG, but for five reasons not all of the IgG detected. First, the concentration of anti-Fab and anti- $\mathrm{F}\left(\mathrm{ab}^{\prime}\right)_{2}$ antibodies detected in RA patients is usually around $5 \mu \mathrm{g} / \mathrm{ml}(14,15)$; whereas, our IgG levels detected in the IC in six patients were $>70 \mu \mathrm{g} / \mathrm{ml}$ and at least $10 \mu \mathrm{g} / \mathrm{ml}$ in the other nine JRA patients. Second, a recent study of IEF on anti-Fab antibodies demonstrated the majority was of the isotypes IgG4 and $\operatorname{lgG} 3$, especially the acidic clonally restricted anti-Fab antibodies (16). Our IC were also acidic clonally restricted in the $\mathrm{pH}$ range $4.0-5.5$, but have been shown by specificity studies to be mainly $\mathrm{IgGl}$ antibodies directed toward $19 \mathrm{~S} \mathrm{IgM} \mathrm{RF}$ and hidden 19S IgM RF in JRA patients $(18,19)$. Third, specificity studies performed in detail showed the binding site for the IgM RF to be in the $\mathrm{C}_{\gamma} 3$ homology area of the IgGl molecule, not in the $\mathrm{C} \gamma \mathrm{l}$ or hinge region as for the anti-Fab and anti- $\mathrm{F}\left(\mathrm{ab}^{\prime}\right)_{2}$ antibodies (18). Fourth, they would not explain the IgG RF being present in the eluates. There would have to be complete cross reactivity between the anti-Fab and anti-F $\left(\mathrm{ab}^{\prime}\right)_{2}$ antibodies and IgG RF, because in most patients with JRA IgG RF levels are $>10 \mu \mathrm{g} / \mathrm{ml}$ (20). Fifth, the sera of four patients with high levels of IgG in their glycine- $\mathrm{HCl}$ eluates demonstrated no IgG in their $\mathrm{NH}_{3}$ or glycine- $\mathrm{HCl}$ eluates from the affinity column which had $\mathrm{F}\left(\mathrm{ab}^{\prime}\right)_{2}$ fragments of goat IgG of no immunologic specificity bound.

The 19S IgMRF-IgG and 19S IgM RF-7S IgG RF IC were detected by IEF predominantly in the restricted spectrotypic pattern of the $\mathrm{pH}$ range of 4.0-5.5. 19S IgM RF could be detected throughout the $\mathrm{pH}$ range, but predominantly between 4.0-5.5 and IgG RF could only be demonstrated in the range of 4.0-5.5. The significance of this clonal restricted pattern needs further elucidation. The total restriction of the $19 \mathrm{~S}$ IgM RF and 7S IgG RF IC material in RA had been suggested previously. Trieshmann et al. (21) using liquid sucrose gradient IEF demonstrated that anti-IgG antibodies were restricted to the acidic proteins. Similarly, Höffken et al. (22) have demonstrated clonally restricted IC in vitro by preparation of human serum albuminantihuman serum albumin IC. They demonstrated human serum albumin-antihuman serum albumin IC only in the $\mathrm{pH}$ range of $4.5-5.0$, similar to our IC in JRA. These acidic clonally restricted IC identified in our JRA patients, therefore, could play a part in pathogenesis. Using $19 \mathrm{~S}$ IgM RF and $7 \mathrm{~S}$ IgG RF as markers for the identification of the IC in JRA patients in serial studies may lead to the demonstration of a more aggressive disease, a poorer prognosis, and therefore to possibly be more aggressive with treatment. It also opens up a new area for future research. The ability to further define the constituents of these IC may aid in determining the underlying antigen and disease pathogenesis in JRA. Work on evaluating these IC for glycolipids of viral origin, glycosaminoglycans, and peptidoglycan-polysaccharides of bacterial origin is in progress.

\section{REFERENCES}

1. Moore TL, Weiss TD 1982 Immunologic studies in juvenile arthritis. Bull Rheum Dis 32:25-29

2. Miller JJ, Osborn CL, Hsu Y-P $1980 \mathrm{Clq}$ binding in serum in juvenile rheumatoid arthritis. J Rheumatol 7:655-670

3. Moore TL, Sheridan PW, Traycoff RB, Zuckner J, Dorner RW 1982 Immune complexes in juvenile rheumatoid arthritis: a comparison of four methods. J Rheumatol 9:395-401

4. Latzka U, Menzel EJ, Granninger W, Steffen C 1984 Immune complexes in juvenile chronic arthritis. Rheumatol Int 4:45-48

5. Moore TL, Zuckner J, Baldassare AR, Weiss TD, Dorner RW 1978 Complement-fixing hidden rheumatoid factor in juvenile rheumatoid arthritis. Arthritis Rheum 21:935-941

6. Moore TL, Dorner RW, Weiss TD, Baldassare AR, Zuckner J 1980 19S IgM hidden rheumatoid factor in juvenile rheumatoid arthritis. Pediatr Res 14:1135-1138

7. Moore TL, Sheridan PW, Zuckner J, Dorner RW 1983 Separation and characterization of immune complexes containing 19S IgM rheumatoid factor-IgG in juvenile arthritis. Arthritis Rheum 26:165-169

8. Moore TL, Dorner RW, Sheridan PW, Zuckner J 1984 Precipitation of 19 S IgM rheumatoid factor-IgG circulating immune complexes in patients with juvenile arthritis by polyethylene glycol and separation by immobilized protein A. Clin Exp Immunol 56:247-252

9. Moore TL, Dorner RW 1986 Separation and characterization of complementfixing immune complexes in juvenile rheumatoid arthritis patients. Rheumatol Int 6:59-62

10. Brewer EJ, Bass J, Baum J, Cassidy JT, Fink C Jacobs J, Hanson V, Levinson JE, Schaller J, Stillman JS 1977 Current proposed revision of JRA criteria. Arthritis Rheum 20(suppl): 195-199

11. Jones VE, Cowley PJ, Allen C, Elson CJ 1980 The isolation of immune complexes containing IgM rheumatoid factor and recovery of IgG rheumatoid from the complexes. J Immunol Meth 37:1-14

12. Faith A, Pontesilli O, Unger A, Panayi GS, Johns P 1982 ELISA assays for IgM and IgG rheumatoid factors. J Immunol Meth 55:169-177

13. Manrique A, Lansky M 1981 Agarose-Sephadex: a new improved matrix for preparative flatbed isoelectric focusing. Electrophoresis 2:315-320

14. Nasu H, Chia DS, Knudsen DW, Barnett EV 1980 Naturally occurring human antibodies to the $\mathrm{F}\left(\mathrm{ab}^{\prime}\right)_{2}$ portion of IgG. Clin Exp Immunol 42:378-386

15. Birdsall HH, Lidsky MD, Rossen RD 1983 Anti-Fab' antibodies in rheumatoid arthritis. Arthritis Rheum 26:1481-1492

16. Persselin JE, Stevens RH 1985 Anti-Fab antibodies in humans. J Clin Invest 76:723-730

17. Olds LC, Miller JJ 1984 Anti-F( $\left(\mathrm{ab}^{\prime}\right)_{2}$ antibodies that interfere with interpretation of the anti-C3 assay for immune complexes with rheumatic diseases. Arthritis Rheum 27:330-336

18. Moore TL, Dorner RW, Weiss TD, Baldassare AR, Zuckner J 1981 Specificity of hidden 19S IgM rheumatoid factor in patients with juvenile rheumatoid arthritis. Arthritis Rheum 24:1283-1290

19. Emancipator K, Moore TL, Dorner RW, Sheridan PW, Eisenwinter RK, Zuckner J 1985 Hidden and classical 19 S IgM rheumatoid factor in a juvenile arthritis patient. J Rheumatol 12:372-375

20. Wernick R, LoSpalluto JJ, Fink CW, Ziff M 1981 Serum IgG and IgM rheumatoid factors by solid-phase radioimmunoassay. Arthritis Rheum 24:1501-1511

21. Trieshmann HW, Abraham GN, Santucci EA 1975 The characterization of human anti-IgG autoantibodies by liquid isoelectric focusing. J Immunol 114:176-181

22. Höffken K, Bosse F, Steih U, Schmidt CG 1982 Dissociation and isolation of antigen and antibody from immune complexes. J Immunol Meth 53:51-59 